\title{
A young woman with mucocutaneous pigmentation and intestinal polyps
}

DOI: $10.12809 /$ hkmj133753

\begin{abstract}
A 26-year-old woman was regularly followed up in a gastro-intestinal out-patient clinic. Since early childhood, she was noted to have hyperpigmented lesions over the perioral region (Fig 1a) and fingers (Fig 1b), and a history of small intestinal intussusception due to polyps that was treated by surgery when she was 12 years old. Endoscopic assessment revealed multiple gastric polyps (Fig 1c) and a colonic hamartoma (Fig 1d). The family history was otherwise unremarkable for gastro-intestinal disease or malignancy.
\end{abstract}

\section{Questions}

1. What is the diagnosis?

2. Is genetic testing available for this disease?

3. How should the patient's problem be managed?

\section{Answers}

1. Peutz-Jeghers syndrome (PJS).

This rare autosomal dominant polyposis syndrome has a point prevalence of 1 in 50000 to 200000 live-births, characterised by multiple gastrointestinal hamartomatous polyps, mucocutaneous pigmentation, and an increased cancer risk. It is caused by germline mutation of the serine-threonine kinase 11 (STK11) gene. ${ }^{1}$ About half of the patients are simplex cases due to de-novo mutations and have no

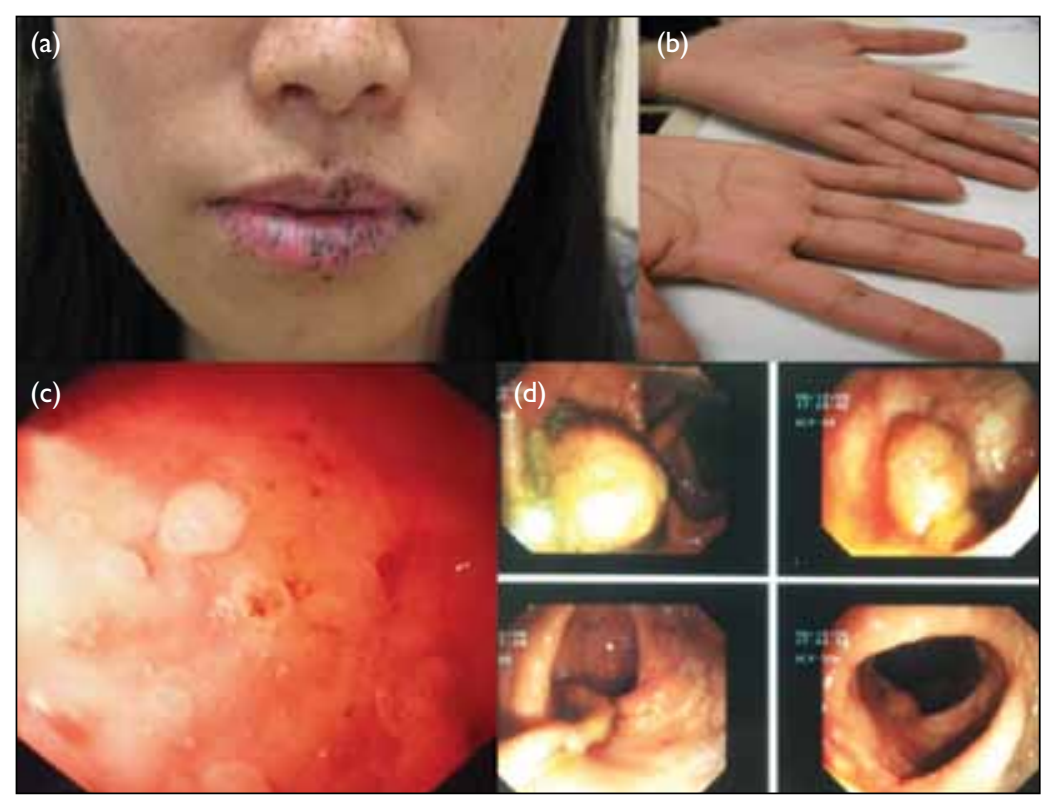

FIG I. Clinical presentation of the patient

\section{family history.}

The clinical manifestations are age-dependent. In infancy, more than $95 \%$ of the patients have mucocutaneous pigmented lesions over the perioral, perianal and/or digital regions that may fade after puberty. In childhood, polyp-related symptoms like gastro-intestinal bleeding, anaemia, abdominal pain due to intussusception, obstruction, or infarction become predominant.

The histology of Peutz-Jeghers (PJ) polyps is distinctive, there being a polypoid, hyperplastic mucosa, and bands of arborising smooth muscle. The clinical diagnosis of PJS can be made when patients meet one of the following criteria²:

(1) Two or more histologically confirmed PJ polyps;

(2) Any number of PJ polyps with a positive family history of PJS in close relative(s);

(3) Characteristic mucocutaneous pigmentation with a positive family history of PJS in close relative(s); or

(4) Any number of PJ polyps with characteristic mucocutaneous pigmentation.

2. In an appropriate clinical setting, testing for the STK11 gene can be undertaken. By sequencing and gene dosage analysis (like the multiplex ligationdependent probe amplification method), pathogenic mutations can be identified in almost all clinically diagnosed PJS patients with a positive family history and $90 \%$ of those without a family history. Apart from confirming the diagnosis, it is useful for presymptomatic testing of other at-risk family members, as well as to enable prevention by means of obtaining a prenatal or preimplantation genetic diagnosis. Therefore, genetic testing should be considered for all PJS patients (Fig 2).

3. The relative cancer risk for PJS patients is 9 to 18 times higher than in the general population, ${ }^{3}$ and particularly for luminal gastro-intestinal cancers and for breast cancers. The risk is even higher in persons age over 50 years. Therefore regular gastro-intestinal screening and tumour surveillance is essential for all PJS patients, not only for early detection of tumour, but also to prevent polyp-related complications. The recommendations on surveillance based on the best current evidence are summarised in the Table. ${ }^{2}$

Endoscopic polypectomy should be performed for polyps larger than $1 \mathrm{~cm}$. Large small intestinal polyps can be removed by balloon enteroscopy or sometimes surgery. Although no pharmacological treatment or prophylaxis is recommended for PJS, 
(a)

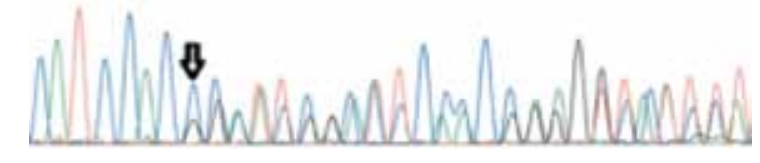

(b)

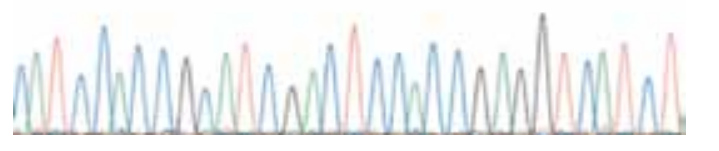

FIG 2. DNA sequence chromatographs of the patient

(a) Heterozygous c.82delC mutation in exon I of STK I I gene was detected. (b) Wide-type sequence for comparsion

TABLE. Recommendations for surveillance and follow-up for patients with Peutz-Jeghers syndrome ${ }^{2}$

\begin{tabular}{|c|c|c|}
\hline System & Examination* & Results \\
\hline General & $\begin{array}{l}\text { Annual physical examination; annual blood test (include complete blood } \\
\text { count and liver function test) }\end{array}$ & - \\
\hline \multirow[t]{3}{*}{ Gastro-intestinal } & Baseline OGD/colonoscopy at the age of 8 years & $\begin{array}{l}\text { Polyps detected: repeat } 3 \text { yearly till } 50 \text { years old } \\
\text { No polyps detected: repeat at the age of } 18 \text { years, } \\
\text { then } 3 \text { yearly till } 50 \text { years old }\end{array}$ \\
\hline & VCE every 3 yearly from the age of 8 years & - \\
\hline & Colonoscopy every $1-2$ yearly after 50 years old & - \\
\hline \multirow[t]{2}{*}{ Reproductive } & For males: annual testicular examination from birth till 12 years old & Ultrasound testis if abnormality detected \\
\hline & $\begin{array}{l}\text { For females: cervical smear with liquid-based cytology every } 3 \text { years after } \\
\text { the age of } 25 \text { years }\end{array}$ & - \\
\hline \multirow[t]{2}{*}{ Breast (female) } & Monthly examinations from the age of 18 years & - \\
\hline & $\begin{array}{l}\text { Annual breast MRI from } 25 \text { to } 50 \text { years old; annual mammography } \\
\text { thereafter }\end{array}$ & - \\
\hline
\end{tabular}

* OGD denotes oesophagogastroduodenoscopy, VCE video capsule endoscopy, and MRI magnetic resonance imaging

therapeutic agents that inhibit the mTOR and COX2 pathways are potential drugs that might modulate and slow down the development of PJ polyps, and are currently under study in experimental trials. The pigmented skin lesion has no malignant potential as it is a melanin deposit. For cosmetic purposes, intense pulsed light and laser therapy may be useful for selected patients.

Finally, as PJS is a hereditary polyposis syndrome, genetic evaluation and counselling for patients and at-risk family members by a clinical geneticist is indicated.
HM Luk, FHKAM (Paediatrics)

Email: luksite@gmail.com

Ivan FM Lo, FHKAM (Paediatrics)

Clinical Genetic Service, Department of Health, Hong Kong

Kelvin MC Yu, FHKAM (Medicine)

Department of Medicine

Tuen Mun Hospital, Tuen Mun, Hong Kong

Tony MF Tong, MSc

Stephen TS Lam, FHKAM (Paediatrics)

Clinical Genetic Service, Department of Health, Hong Kong

\section{References}

1. Jenne DE, Reimann H, Nezu J, et al. Peutz-Jeghers syndrome is caused by mutations in a novel serine threonine kinase. Nat Genet 1998;18:38-43. cross ref

2. Beggs AD, Latchford AR, Vasen HF, et al. Peutz-Jeghers syndrome: a systematic review and recommendations for management. Gut 2010;59:975-86 cross ref.

3. van Lier MG, Westerman AM, Wagner A, et al. High cancer risk and increased mortality in patients with Peutz-Jeghers syndrome. Gut 2011;60:141-7. cross ref 